\title{
0 processo de formação e institucionalização do Serviço Social como profissão em Cuba
}

\author{
The process to form the professional social worker in Cuba \\ and to institutionalize the profession in that country
}

Josiane Moraes*

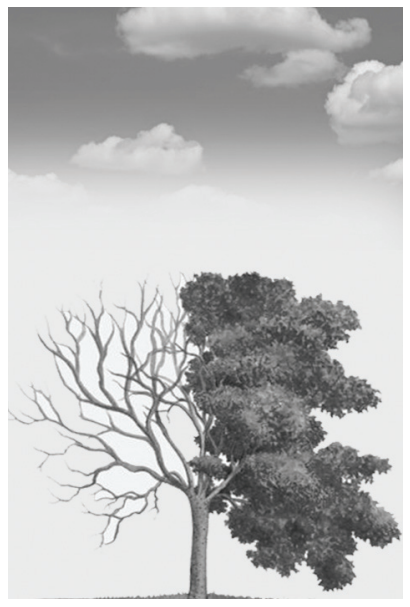

Resumo: Este trabalho apresenta uma recuperação da trajetória do Serviço Social como profissão em Cuba considerando as transformações sociais, econômicas e políticas que o país tem apresentado desde a década de 1930. O caminho metodológico percorrido foi pesquisa bibliográfica e documental, bem como utilizou-se das informações coletadas junto aos assistentes sociais cubanos durante a participação no VI Congresso Internacional de Trabajo Social realizado em maio de 2011 em Havana, Cuba. O Serviço Social ganhou destaque na sociedade cubana a partir da década de 1990. Em 2000 inicia-se um processo mais sólido do ponto de vista da institucionalização e da profissionalização da profissão no país.

Palavras-chave: Trajetória do serviço social cubano. Institucionalização. Formação profissional.

\begin{abstract}
This paper recovers the trajectory of social work as a profession in Cuba, considering the social, economic and political transformations that the country has been facing since the 1930s. The methodological approach was driven by documentary and bibliography research, as well as the use of some information collected from Cuban social workers during the VI International Congress of Social Work held in Havana, Cuba, May 2011. Social work has been highlighted in the Cuban society from the 1990s. In 2000 a more solid process to institutionalize and to give a professional feature to social work started in the country.
\end{abstract}

Keywords: Social work trajectory in Cuba. Institutionalization. Professional training.

* Graduada em Serviço Social pela Universidade Federal de Santa Catarina, mestranda do Programa de Estudos Pós-graduados em Serviço Social na Pontifícia Universidade Católica de São Paulo — São Paulo, Brasil.E-mail: eujomoraes@yahoo.com.br. 


\section{Introdução}

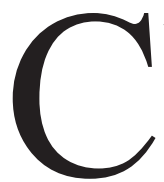

uba constitui-se uma das ilhas do Caribe localizada ao norte da América Central com aproximadamente 11 milhões de habitantes, cuja língua oficial é o espanhol e Havana é a capital do país. Este país, não muito diferente dos demais da América Latina, foi descoberto em 1492 pelo navegador Cristóvão Colombo, e por quatro séculos Cuba esteve sob o domínio da Espanha. O Partido Revolucionário Cubano, PRC, criado em 1892 pelo poeta e escritor José Martí, liderou as primeiras lutas pela independência e abolição da escravatura no país. Contudo, a independência de Cuba somente ocorreu no final de 1898, com a assinatura do Tratado de Paris entre a Espanha e os Estados Unidos da América. Ou seja, era o fim da dominação espanhola, mas representaria o início da dominação norte-americana que no início de 1899 estabeleceu um governo militar na ilha (Sanchez, 2009).

Somente em maio de 1902 foi proclamada a República de Cuba e o país foi transformado em uma colônia americana marcada pela existência de cassinos e cabarés e por refúgio de ricos, magnatas e mafiosos americanos. "Ao lado de grandes mansões de veranistas e ricos norte-americanos o povo cubano convivia com a pobreza, a submissão, com mais de $30 \%$ de analfabetos, e grande parte da população estava à margem de serviços essenciais como moradia e saúde" (Campagnucio, 2004, p. 3). Tal realidade permaneceu em Cuba por algumas décadas, e somente em dezembro 1956 vai ocorrer a tão conhecida Revolução Cubana liderada por Fidel Castro com o apoio de Ernesto Che Guevara e outros oitenta combatentes. As revoltas perduraram até 1959, quando o chamado "Exército Rebelde" derrotou as forças do ditador Fulgêncio Batista e assumiu o poder na Ilha.

Uma das primeiras medidas do novo governo foi nacionalizar as empresas estrangeiras, inclusive as norte-americanas. Como consequência, as relações diplomáticas com os Estados Unidos da América foram cortadas, e a partir de 1962 se estabeleceu um embargo econômico, comercial e financeiro a Cuba, o qual permanece até hoje.

Cuba passou sessenta anos dependendo dos Estados Unidos para tudo. A economia, a tecnologia, a indústria, a educação, a cultura, a alimentação, o fornecimento de petróleo, a venda de açúcar [...]. Com o bloqueio total, decretado pela Organização dos Estados Americanos [...], Cuba viveu momentos duros e só podia comprar o que fosse absolutamente indispensável para a vida do país. Os carros foram um bom exemplo desse comportamento: decidiu-se sobreviver com os carros americanos que existiam, e tentar mantê-los inteiros até que a situação melhorasse e a frota nacional pudesse ser substituída por outros modelos. Durante dez anos, não entrou no país um 
só parafuso feito nos Estados Unidos, embora praticamente todos os carros fossem americanos. [...] A preocupação do governo com a manutenção de altos níveis de produtividade da cana-de-açúcar é óbvia: além de representar quase $50 \%$ do Produto Nacional Bruto do país, nenhum cubano se esquece de que essa cultura foi um dos principais fatores que permitiram que o país sobrevivesse ao bloqueio econômico decretado em 1962. (Morais, 1976, p. 23, 24, 54)

Desde então, Cuba se considera um país de sistema socialista, baseado nos princípios da equidade e da justiça social, o qual busca o desenvolvimento por uma perspectiva integral, chamada a transformar as condições de vida, a estrutura social e o comportamento dos indivíduos. Essas são definições que regem o caráter das políticas sociais e, portanto, definem o papel e o alcance do Serviço Social na Ilha (Gutierrez e Barroso, 2005).

A partir dessas transformações societárias, as quais repercutem na gênese do Serviço Social cubano, é que se pretende fazer apontamentos sobre a história, a formação e a prática profissional do Serviço Social. ${ }^{1} \mathrm{O}$ caminho metodológico percorrido foi pesquisa bibliográfica e documental. Convém ressaltar o escasso material publicado sobre a história do Serviço Social em Cuba, tanto em livros, artigos, quanto nos sites oficiais cubanos. Foram de grande valia as informações verbais coletadas durante a participação no VI Congresso Internacional de Trabajo Social realizado em maio de $2011^{2}$ em Havana, Cuba.

O Serviço Social ganhou destaque na sociedade cubana a partir da década de 1990. Em 2000 iniciou-se um processo mais sólido do ponto de vista da institucionalização e profissionalização da profissão no país. Não existe em Cuba uma carreira universitária que trate especificamente de Serviço Social, embora exista a possibilidade de fazer o mestrado em Serviço Social. Os profissionais que atuam como assistentes sociais possuem formação de nível básico a partir das Escolas de Formação de Tralhadores Sociais (EFTS), de nível médio a partir das escolas técnicas, cuja formação de dois anos está voltada para área da saúde, ou então fazem a graduação em Sociologia ou Reabilitação Social e Terapia Ocupacional, que proporciona saída à especialização em Serviço Social. Na sua maioria, os mestran-

1. O interesse por tal pesquisa foi sucitado após a participação no VI Congreso Internacional de Trabajo Social. VIII Congreso Nacional de Trabajadores Sociales de la Salud e o II Congreso Nacional e Internacional de Reahabilitación Social y Ocupacional realizado em maio de 2011 na cidade de Havana. Salienta-se que enquanto aluna do mestrado do Programa Pós-Graduados em Serviço Social da Pontifícia Universidade Católica de São Paulo, a participação nesse evento foi viabilizada com o financiamento Capes (Coordenação de Aperfeiçoamento de Pessoal de Nível Superior).

2. Ver nota de rodapé n. 1 . 
dos em Serviço Social são oriundos dos cursos da área de Ciências Sociais e Humanas. A declaração de Enrique J. G. Cabezas ${ }^{3}$ ajuda a ilustrar essa questão:

[...] muy importante la formación de trabajadores sociales de Cuba, porque no hay una carrera de trabajador social, es urgente e indispensable para la educación universitaria la carrera de trabajador social. Trabajadores sociales de las carreras de posgrado son de diversas áreas humanísticas, el estudio de la ley, los medios de comunicación, la psicología, sino que se conforman con poco carrera trabajo social. Además, los maestros no están capacitados en trabajo social. Es necesario que los profesionales de trabajo social asuman la propiedad de una metodología de la teoría social, que les permitan hacer una práctica social más allá del empirismo. Y así legitimar la profesión en Cuba, Trabajo Social, su institucionalización y fortalecimiento. [...] (Grifos meus)

Segundo Gutierrez e Barroso (2005), os estudiosos e protagonistas da profissão no país têm discutido que o processo de construção do trabajo social como disciplina científica tem sido contraditório, havendo muitas perguntas a serem respondidas em todos os níveis, ou seja, há necessidade de conhecer com propriedade a teoria, os métodos, as práticas, a relação entre o ensino e a pesquisa, bem como de resgatar e aperfeiçoar o processo de profissionalização dos trabalhadores sociais no país. Foram muitos os questionamentos que permearam as reflexões dos palestrantes da mesa-redonda denominada "El Trabajo Social em Cuba" realizada no Congresso Internacional de Trabajo Social em Cuba (maio/2011), quais sejam: como definir o Serviço Social para Cuba? Como alcançar o ensino que permita formar um assistente social integral e não setorializado? Como transformar o caráter assistencialista das práticas do Serviço Social, convertendo os sujeitos em protagonistas da própria transformação? As respostas para tais questionamentos carecem de reflexão analítica das necessidades sociais do atual momento histórico, das condições econômicas, sociopolíticas e culturais que permeiam a realidade cubana.

Em suma, o presente artigo propõe um mergulho nas discussões sobre o processo de institucionalização do Serviço Social como profissão, em seu movimento histórico e teórico na sociedade cubana. O marco temporal do trabalho inicia na década de 1930, percorrendo as transformações ocorridas até os anos 2000.

3. Informação verbal: mesa-redonda realizada no VI Congreso Internacional de Trabajo Social. VIII Congreso Nacional de Trabajadores Sociales de la Salud. II Congreso Nacional e Internacional de Reahabilitación Social y Ocupacional realizado em maio de 2011 em Havana, Cuba. O tema abordado foi: "El Trabajo Social em Cuba", com os palestrantes Odalys G. Jubán, Maria Teresa C. Rivacoba e Enrique J. G. Cabezas. 


\section{As primeiras iniciativas de desenvolvimento do Serviço Social cubano na década de 1930}

O status científico do trabajo social em Cuba tem sido objeto de diversas controvérsias desde a sua criação no século XIX e início do XX. Alguns o consideram uma arte ou tecnologia, ciência ou disciplina científica; outros uma profissão. Como disciplina científica, afirma-se que ainda está em construção e tem tomado como aporte teórico e metodológico conteúdos da sociologia, psicologia, antropologia, economia, história e direito. ${ }^{4}$

Na segunda metade do século XIX, a concepção de filantropia começou a se manifestar em Cuba no momento em que surgiram as chamadas Sociedades de Instrucción, Recreo y Socorro. Entre os anos 1920-50, a iniciativa surgiu a partir de artesãos e trabalhadores como um meio de contribuir para o desenvolvimento social, educacional e cultural da população. Ajudava-se também nas questões relacionadas a doenças, pagamento de funeral em caso de morte, bem como no auxílio das famílias. Durante a primeira década do século XX, era obrigatório estudar as questões relacionadas ao bem-estar da população cubana, principalmente em instituições privadas e da Igreja Católica. Esse cuidado e caridade têm forte inspiração americana, que prioriza o tratamento de problemas individuais, deixando de olhar a origem dos problemas que se apresentavam (Lima, 1983).

Nesse sentido, e de modo não muito diferente dos outros países, a origem do trabajo social em Cuba possuiu forte relação com a Igreja Católica e com as associações beneficentes que desenvolviam atividades para "socorrer" a população socialmente desfavorecida. Recorda-se da trajetória do Serviço Social brasileiro, conforme aponta Yazbek (2009), quando a relação entre a profissão e o ideário católico imprimia um caráter de apostolado fundado em uma abordagem dos problemas sociais enquanto problema moral e religioso, numa intervenção que prioriza a formação da família e do indivíduo para solução dos problemas e atendimento das suas necessidades materiais, morais e sociais.

Nos anos 1930, existiram indícios de preocupação com as pessoas que trabalhavam em instituições filantrópicas, observava-se a necessidade de algum conhecimento que permitisse a essas pessoas lidar de forma mais rigorosa com assuntos pertinentes à assistência social. Em 1938, por iniciativa da Sociedade Lyceum, criou-se o Conselho de Assistência Social. A Sociedade Lyceum foi constituída por um grupo de mulheres que afirmavam que por meio da educação e da cultura seria

4. Idem nota 3 . 
possível resolver os problemas sociais. ${ }^{5}$ Diante das necessidades sociais que se estabeleciam, a Sociedade Lyceum clamava por criar uma escola de Serviço Social em Havana.

Nesse mesmo período promulgou-se a Constituição cubana de 1940, a qual reconheceu pela primeira vez a responsabilidade do Estado com a seguridade e a assistência social, sendo esta ligada ao Ministério da Salubridade. O processo caminhava para a abertura da primeira escola de Trabajo Social, cujo mérito foi do Conselho de Assistência Social, o qual recebeu apoio da Universidade de Havana e recursos financeiros da prefeitura. Em 1943 inaugurou-se a primeira escola de Trabajo Social em Cuba ligada à Faculdade de Educação da Universidade de Havana, que em 1945 tornou-se Instituto de Serviço Social da Faculdade de Ciências Sociais e Direito Público. Esse processo também culminou na criação da primeira Associação de Assistentes Sociais de Cuba em 1947, dada a necessidade que existia de consolidar a categoria profissional, a fim de alcançar recursos para concretizar as ações de bem-estar social (Jubán et al., 2009). A partir daí, o Serviço Social cubano começa a ser desenvolvido profissionalmente, porém os serviços sociais continuavam com um viés assistencialista, de ajuda e benemerência que serviam apenas para amenizar as necessidades da população.

De acordo com Gutierrez e Barroso (2005), os interessados em entrar na escola de Trabajo Social deveriam atender a alguns requisitos, tais como: apresentar boa índole, respeito e dignidade pelo ser humano, ter no máximo 35 anos de idade, possuir bacharelado, preferencialmente na área de Letras ou ter concluído o Ensino Médio em escola americana (podendo a escola localizar-se em Cuba ou nos Estados Unidos). Em caso de não cumprir esses critérios, foram aceitos alunos que passaram nos exames de admissão ou graduados da escola de Enfermagem, do Lar, Comércio, Artes e Ofícios e Técnicas Industriais.

O plano de estudos da escola constituía-se em dois anos divididos em quatro semestres, sendo que as disciplinas eram relacionadas às áreas de Psicologia, Sociologia, e tinha-se princípios básicos de Ciências Médicas, bem como aulas de Direito relacionado à assistência social. Os estágios abarcavam intervenções nos campos "médico-sociais", criminalidade juvenil, crianças abandonadas e trabalho com grupos em diversas instituições. De maneira geral, das 26 disciplinas do plano de estudos, seis estavam relacionadas à área médica, e mesmo tendo sido diminuí-

5. Para saber mais sobre a Sociedade Lyceum ver: La conspiración de las lectoras de José Antonio Marina y María Teresa Rodríguez de Castro. Barcelona: Editorial Anagrama, 2009. 280 p. (Col. Biblioteca de la Memoria.) 
do para 23 disciplinas a partir de 1952, elas continuavam a ter forte relação com a saúde (Jubán et al., 2009).

A profissão, em sua gênese, possuía relação direta com a medicina. As privações ou desvantagens sociais eram problemas individuais tratados superficialmente nos seus efeitos, deixando de lado a ação sobre suas causas e a influência dos determinantes sociais. Sem obter êxito na formação acadêmica em Serviço Social, em 1956 o governo liderado pelo presidente Fulgêncio Batista y Zaldivar (1934-59), forte defensor dos interesses dos Estados Unidos por motivos políticos relacionados com a insurreição na ilha, decidiu pelo fechamento das universidades públicas, interrompendo, consequentemente, os estudos de Serviço Social por muitos anos. ${ }^{6}$

\subsection{Serviço Social em Cuba após 1959}

Nossotros llamamos Pueblo si de lucha se trata, a los sescientos mil cubanos que estan sin trabajo [...]; A los quinientos mil obreiros del campo que habitan en bohios miserables [...]; Esse es el pueblo el que sufre todas las desdichas y es por tanto capaz de pelear com todo coraje! La história me absolvera.

(Trecho da fala de Fidel Castro extraído da exposição do Museu da Revolução Cubana em Havana, Cuba)

A vitória revolucionária em Cuba através da guerra popular liderada por Fidel Castro foi uma conquista decisiva na história da ilha. O profundo significado social da Revolução Cubana permitiu ir além da perseguição norte-americana, assim como das metas antiditatoriais e democráticas. Recuperou-se a plena soberania nacional para erradicar a raiz da exploração do homem sobre o homem e construir uma sociedade mais justa e igualitária. Foi implementado pela primeira vez o princípio de que todas as pessoas, independentemente da sua origem ou status, teriam o direito de conhecer e participar de todos os bens materiais e culturais que a sociedade tem, bem como teriam o dever de contribuir e se desenvolver para o crescimento de todos. Desta maneira, a Revolução Cubana transitou radicalmente da etapa democrático-popular, agrária e anti-imperialista à socialista, em $1961 .^{7}$

6. Informação verbal, cf. nota 3.

7. Informação verbal: palestra realizada na XIX Convenção Nacional de Solidariedade a Cuba nos dias 23 a 26 de junho de 2011 na cidade de São Paulo. O tema da palestra foi "A importância da revolução Cubana no marco dos 50 anos da vitória em Playa Girón e a solidariedade internacional”. Os participantes da mesa foram o 
Com o triunfo da revolução, cujos príncipios de justiça social e equidade social através dos quais se objetivava construir um novo projeto social, supunha-se que não haveria desigualdade social, não haveria pobres, nem ricos, não haveria quem não tivesse acesso à cultura, ao lazer, à habitação, à saúde, ao esporte. Portanto, pensando por esse prisma, não teria sentido a formação em Serviço Social, a qual estava extinta desde $1956 .{ }^{8}$

Nesse sentido, em fevereiro de 1959 foi criado o Ministério do Bem-Estar Social, cujo objetivo era realizar o cuidado, a prevenção, a assistência e a reabilitação de indivíduos e grupos, permitindo o gozo de viver em harmonia com o sistema. Os problemas sociais que existiam, como prostituição, crianças órfãs, grupos da população que tivessem problemas sociais, seriam cuidados. Esse Ministério foi inserido como um instrumento para a realização das políticas sociais estabelecidas pela revolução e como parte do novo sistema político restaurado após o triunfo revolucionário. Contudo, quando os programas sociais já estavam em andamento, deixou de existir o Ministério do Bem-Estar Social, pois pensava-se que em pouco tempo já não haveria mais problemas sociais. As responsabilidades pelo planejamento e execução dos serviços sociais foram transferidas para o Ministério de Saúde Pública, o Ministério da Educação, entre outros órgãos (Jubán et al., 2009).

Mais uma vez se reafirma a não necessidade de existir a carreira de Serviço Social. Gutierrez e Barroso (2005, p. 6) se recordam de que nessa época "de los países socialistas solo en Checoslovaquia existían escuelas de trabajo social”.

Por outro lado, como afirmou Cabellero, "'En Cuba somos 'doctores' en crear organizaciones y estructuras". Significa que o Ministério do Bem-Estar Social pode ter sido extinto, entretanto ocorria o surgimento de novas organizações revolucionárias como a Associação de Jovens Rebeldes (AJR) criada em 28 de janeiro de 1960, a Federação de Mulheres Cubanas, criada em 23 agosto de 1960, o Comitê de Defesa da Revolução (CDR), criado em 28 de setembro de 1960, e a Associação Nacional de Pequenos Agricultores (Anap), criada em maio de 1961. Além disso, em 2 de dezembro de 1960 foram criadas as Escolas de Instrução Revolucionária (EIR), objetivando formação marxista. Essas organizações seriam capazes de detectar em cada quadra, em cada bairro onde estavam os problemas sociais que requeriam ajuda, tornando-se os facilitadores das políticas sociais.

coronel Jorge Herrera Medina (combatente na batalha de Girón); Kênia Serrano Puig (presidente do Instituto Cubano de Amizade aos Povos) e Dôra Cesar (representante do Núcleo de Estudos sobre Cuba — Nescuba).

8. Informação verbal, cf. nota 3.

9. Idem. 
Convém explicitar alguns aspectos dos Comitês de Defesa da Revolução (CDR). São organizações não governamentais, as quais reúnem voluntariamente a população acima de catorze anos, independentemente de cor, sexo, idade ou status social. Nesses Comitês, todos trabalham em benefício da comunidade/bairro. Estão organizados em todo o território cubano - nas áreas urbanas e rurais estima-se que existam, atualmente, cerca de 122 mil CDRs em todo o país com mais de 8 milhões de membros, os quais são eleitos democraticamente pelos moradores do bairro. A princípio a sua tarefa principal era mobilizar toda a sociedade na defesa da revolução e nas conquistas do socialismo. Atuavam em campanhas de vacinação e alfabetização. Atualmente, além dessas questões, fazem trabalhos com crianças e idosos, cuidam da beleza dos bairros, das escolas, recolhem matérias-primas, organizam as eleições de poder popular, ${ }^{10}$ entre outras atividades. ${ }^{11}$

Entre as ações realizadas pelo CDR, convém destacar as atividades realizadas em prol da educação/alfabetização a partir de 1960. Um dos preceitos básicos da Revolução Cubana é "ser culto para não ser enganado", ou seja, para que ocorra um processo revolucionário, o povo precisa saber o que faz e o que assina. Nesse sentido, um dos grandes projetos de Fidel após a Revolução foi alfabetizar toda a população cubana. ${ }^{12}$ A partir de 1959 a educação em Cuba é gratuita e de qualidade desde as séries iniciais até a faculdade. Criou-se o Ministério da Educação, que trata das questões relacionadas ao ensino primário ( $1^{\mathrm{a}}$ a $6^{\mathrm{a}}$ série), ensino secundário ( $7^{\mathrm{a}}$ a $9^{\mathrm{a}}$ série) e o ensino pré-universitário $\left(10^{\circ}, 11^{\circ}\right.$ e $12^{\circ}$ anos $)$. Para cuidar do ensino universitário foi criado o Ministério da Educação Superior, responsável pela educação técnica (atualmente a educação técnica conta com 322 centros de cursos técnicos profissionalizantes, 152 escolas de comércio, em torno de 300 mil alunos desde 2008), pelas graduações e pós-graduações. ${ }^{13}$

Cabe também uma reflexão acerca da atuação da Federação das Mulheres Cubanas (FMC), cuja organização teve forte influência na instituição do trabalho

10. El Poder Popular en Cuba se genera desde Circunscripciones de base y Consejos populares, que agrupan a los vecinos en cada uno de los 169 municipios del país y desde donde surgen los candidatos propuestos y electos por el voto del pueblo para conformar las estructuras de gobierno, en expresión de democracia participativa total. Disponível em: $<$ http://www.ecured.cu/index.php/Poder_Popular $>$. Acesso em: 27 jun. 2011.

11. Disponíveis em: $<\mathrm{http}: / /$ www.ecured.cu/index.php/Comit\%C3\%A9s_de_Defensa_de_la_ Revoluci\%C3\%B3n> e <http://www.cdr.cu/>. Acesso em: 27 jun. 2011

12. Informação verbal: oficina sobre “A política de saúde e educação em Cuba”, realizada no dia 23 de maio como parte da programação da XIX Convenção Nacional de Solidariedade a Cuba nos dias 23 a 26 de junho de 2011 na cidade de São Paulo. A oficina foi ministrada por representante do Instituto Cubano de Amistad con los Pueblos - Icap.

13. Para saber mais sobre a educação em Cuba ver: <http://www.mes.edu.cu/>. 
social comunitário no país. Atualmente a FMC desenvolve políticas e programas destinados a alcançar a plena realização da igualdade entre mulheres em todas as áreas e níveis da sociedade. No início, o objetivo principal foi a incorporação das mulheres na sociedade e no emprego, bem como o programa de mudanças sociais e econômicas em curso no país. ${ }^{14}$

A FMC está estruturada geograficamente em âmbito nacional, estadual e municipal, e sua direção nacional é composta por um Comitê Nacional e uma secretaria encarregada de cumprir as resoluções aprovadas em cada Congresso, órgão máximo de sua direção, que é realizado a cada cinco anos. A Comissão Nacional reúne mulheres que representam todos os setores sociais e aqueles que estão em posições de tomada de decisão dos ministérios-chave no Partido Comunista, sindicatos e outras organizações sociais. A presidente da FMC faz parte do Conselho de Estado da República de Cuba e dirige a Comissão de Assistência às Mulheres, Crianças e Juventude da Assembleia Popular Nacional de Energia.

Segundo Gutierrez e Barroso (2005), os requisitos necessários para ser uma trabalhadora social na FMC são: ter nível de escolaridade mínima até a nona série, ter vocação para ajudar os outros ou para resolver situações que afetam o desenvolvimento das mulheres e da família, e possuir alguma posição política na comunidade. Entre as atividades realizadas pelas trabalhadoras sociais da FMC destacamos: identificar e resolver problemas sociais que afetam as mulheres, as crianças e suas famílias; realizar visitas às famílias com problemas; coordenar as iniciativas de diferentes instituições para dar atenção aos problemas identificados, tais como o Ministério da Educação, Ministério da Saúde Pública (Minsap) e outros.

De acordo com Jubán et al. (2009), a partir das ações realizadas pelas organizações de massa, em 1971 o Ministério de Sáude Pública abre a primeira escola técnica para formar assistentes sociais no estado de Camaguey; no ano seguinte, em 1972, é inaugrada a Escola de Trabalhadores Sociais especializados em psiquiatria vinculados ao Hospital Psiquiátrico de Havana, estendendo-se para outras cidades ao longo dos anos. A ênfase do trabajo social no campo da psiquiatria se deu porque após a Revolução, o Hospital Psquiátrico de Havana impulsionou cursos,

14. Antes da fundação da FMC, houve várias organizações formadas por mulheres que apoiavam o processo revolucionário cubano, tais como: a Unidade de Mulheres Revolucionárias que reuniam grande número de agricultoras; a Brigada Mulher Revolucionária, os Grupos de Mulheres Humanistas, entre outras, que foram fundidas em uma única organização denominada Federação das Mulheres Cubanas.

Disponível em: $<$ http://www.ecured.cu/index.php/Federaci\%C3\%B3n_de_Mujeres_Cubanas $>$. Acesso em: 28 jun. 2011. 
seminários e o movimento de formação da profissão. $\mathrm{O}$ foco era formar pessoas para prestar serviços especializados de assistência social em clínicas e hospitais em Cuba de acordo com o projeto socialista. Novamente, o setor da saúde é majoritário para a formação e atuação do trabajador social.

A forte relação da prática profissional com a saúde não é por acaso. Cabe mencionar que na mesma época intensificava-se a formação de médicos, pois a maioria dos profissionais da área médica deixou o país durante a Revolução e, portanto, havia a necessidade dessa formação profissional. Porém mencionava-se a necessidade de os profissionais terem um olhar diferenciado para o "humano", com espiríto de solidariedade para com o próximo. O príncípio divulgado era: "Não entregue ao outro aquilo que sobra, mas aquilo que tem". Atualmente, a saúde em Cuba é totalmente gratuita, sendo também considerada uma das melhores medicinas preventivas do mundo. Exemplo disso são os médicos de família, os quais atuam diretamente no bairro em que moram, atendendo em média a 120 famílias por mês. Realizam visitas domiciliares para prevenir, atender e acompanhar as famílias, especialmente as que têm crianças e idosos. ${ }^{15}$

Até 1983 havia em Cuba sete escolas técnicas de "Trabajo Social" localizadas nos seguintes estados: ${ }^{16}$ La Habana, Santiago de Cuba, Santa Clara, Camagüey, Pinar del Río, Matanza y Grama. Com um plano de estudos unificado para todas as escolas, as disciplinas estudadas são: Marxismo, Geologia, Psicologia Social, Matemática, História, Castelhano, Leis e Legislação Social. As disciplinas específicas de Serviço Social são: Introdução ao Serviço Social, História do Serviço Social em Cuba, o Serviço Social de Psiquiatria, Serviço Social de Caso (grupo e comunitário) (Lima, 1983).

Se produce una explosión de técnicos en Trabajo Social egresados de estas escuelas, que en 1978 se agrupan en la organización científica llamada Sociedad Cubana de Trabajadores Sociales de la Salud (Socutras), única asociación de este perfil en Cuba, que tiene entre sus múltiples propósitos la divulgación de los principales logros científico-técnicos em el ámbito del Trabajo Social en el campo de la Salud, en la promoción, prevención, asistencia, rehabilitación, investigación y docencia; mediante el intercambio, la discusión frecuente de sus experiencias individuales y colectivas en eventos y actividades científicas. (Jubán et al., 2009, p. 4)

15. Informação verbal, cf. nota 12 .

16. Cuba possui quinze estados e um município especial: Pinar del Río, La Habana, Ciudad de La Habana, Matanzas, Cienfuegos, Villa Clara, Sancti Spíritus, Ciego de Ávila, Camagüey, Las Tunas, Granma, Holguín, Santiago de Cuba, Guantánamo. Disponível em: <http://www.cuba.cu/portal.php>. Acesso em: 28 jun. 2011. 
Nesse sentido, observa-se que a formação em Serviço Social se constituiu, iniciamente, a nível técnico ou, conforme chamado em Cuba, de técnico médio (TM) focado para ensinar e treinar as habilidades no tratamento de casos e prestação de serviços especializados em clínicas e hospitais, bem como na atuação profissional na área de habitação e em escritórios de Previdência Social.

\subsection{Serviço Social cubano a partir da década de 1990}

A realidade social e econômica em Cuba sofreu modificações a partir da final de década de 1980 e inicío da de 1990. Em 1987, as importações procedentes dos países capitalistas sofriam reduções, as taxas de desemprego chegaram a $6 \%$ em 1988 e o índice de mortalidade aumentou. Mudanças que Cuba não havia registrado desde o triunfo da Revolução. Algumas das causas estavam relacionadas com a diminuição das exportações e o aumento do déficit comercial, fato que, pela primeira vez, fez Cuba suspender o pagamento da dívida externa com mais de cem bancos internacionais, resultando na impossibilidade de adquirir recursos e financiamento dos países socialistas (Espinosa, 2004).

En el seno de esas transformaciones, la sociedad cubana resultó impactada por el cambio de escenario geopolítico ante la desaparición de la Unión de Repúblicas Socialistas Soviéticas (URSS) y el recrudecimiento del bloqueo económico. La coyuntura de crisis implicó cambios hacia la proyección externa (inserción del mercado cubano en el mercado internacional signado por la hegemonía del capital transnacionalizado) e interna (cambios en el orden económico, político-ideológico y social), produciendo un viraje de los patrones precedentes de articulación en los que se asentaba las lógicas de organización social en décadas anteriores al '903. Esa realidad contribuyó a la emergencia y/o acentuación de procesos de diferenciación, vulnerabilidad y precariedad de determinados grupos familiares. (Hernández, 2009, p. 30)

A alternativa encontrada para resolver essas questões foi lançada em abril de 1986, durante as sessões do III Congresso do Partido Comunista. Iniciou-se o chamado "processo de correção de erros e tendências negativas", caracterizado por adotar algumas medidas de ajuste na economia, tais como: desmantelar parte do sistema de gestão da economia, os mercados dos agricultores foram fechados, proibiu-se a compra e venda de casas, limitou-se o emprego do profissional autônomo, entre outras medidas aplicadas. Entretanto, as medidas de ajuste sofreram 
críticas, tendo em vista o uso indiscriminado de incentivos materiais, do crescimento da burocracia (aumentou 2,5 vezes entre 1973 e 1984), da análise tecnocrática dos problemas da economia e da sociedade, do desperdício de recursos, os quais não estavam tendo o controle devido, e a corrupção do Estado (Gallardo, Vilaboy e Arana, 2006, p. 79).

Concomitantemente, nesse período assiste-se ao desaparecimento do socialismo na Europa Oriental (1989-90) e à desintegração da União Soviética em 1991. Além disso, o bloqueio econômico por parte dos Estados Unidos a Cuba foi redobrado a partir das Leis Torricelli, aprovadas pelo Congresso dos Estados Unidos em outubro de 1992 com o nome Ley para la Democracia Cubana, que, entre outras medidas punitivas, estabelecia a eliminação das autorizações a empresas norte-americanas radicadas em países de Terceiro Mundo para negociar com Cuba (Idem).

En esta grave situación, y luego de una postergación de siete meses, se reunió el IV Congreso del Partido Comunista de Cuba en octubre de 1991 que transformó sustancialmente el equipo dirigente, $[\ldots]$ propuso una reforma constitucional [...]. A los pocos meses la Constitución de 1976 fue reformada y renovada la Asamblea Nacional [...]. [...] mientras la inmensa mayoría de la población se veía obligada a acudir a $d i$ ferentes formas de resistencia que espontáneamente generó las más creativas actividades para suplir ingresos y resolver los múltiples problemas surgidos con las drásticas restricciones alimenticias, del transporte, la electricidad y en otros rubros básicos de la vida cotidiana [...]. Entre las secuelas de este marcado deterioro del nivel de vida de la población cubana también estuvo el desplome de muchos servicios sociales y el ensanchamiento del mercado negro. (Gallardo, Vilaboy e Arana, 2006, p. 82, grifos meus)

Portanto, diante desse panorama de crise fortalecido pelo influxo de capital estrangeiro, da abertura ao turismo em Cuba, da circulação de duas moedas no país (o peso cubano e o peso cubano convertido), a pobreza e o desemprego excedem as previsões, assim como as diferenças de classe social e econômica pioram. Cabellero afirma que:

Hasta entonces, eran la punta de la pirámide los intelectuales cubanos, las personas con mayor capital humano, con el fin de formar al hombre con su principal objetivo, sin embargo, con el ascenso de este tipo de problemas se queda en el primer punto de la pirámide los titulares de más dinero y poder. En última instancia, no podemos escapar a la globalización, que emerge de la crisis del capitalismo mundial. 
[...] Si ha notado, también, lo que tine una vida mejor, no es necesariamente lo que más trabaja. ${ }^{17}$

Esse contexto sucita o debate sobre a formação e a institucionalização do Serviço Social. Em 1992, um grupo nacional de Serviço Social com representantes do Ministério de Saúde Pública, Ministério da Educação e Ministério de Relações Internacionais, com a Federação das Mulheres Cubanas organizam uma oficina denominada "Identidad profesional del Trabajo Social" com o objetivo de discutir o perfil do Serviço Social, analisar o programa de formação e promover ações concretas. As estratégias apontadas foram: criar programas universitários (PU) e criar "Escuelas de Formación de Trabajadores Sociales" (EFTS), que oferecessem programas de curto prazo para treinamento de jovens. Após fazer o treinamento, os jovens deveriam regressar às suas comunidades para trabalhar como assistentes sociais. Entretanto, as mudanças não foram muitas, tampouco concretizadas de imediato (Gutierrez e Barroso, 2005).

Mesmo sem estabeler a graduação em Serviço Social, foi criado em 1995 um Programa de Mestrado em Serviço Social na Universidade de Camaguey, que permitiu capacitar profissionais de diferentes áreas do saber, especialmente de humanidades que já realizavam ações no âmbito social e se dispunham a fazer o mestrado em Serviço Social (Jubán et al., 2009).

Em 1998, mediante um esforço conjunto do Ministério da Saúde Pública (Minsap), da Sociedad Cubana de Trabajadores Sociales de la Salud (Socutras) e da Federação das Mulheres Cubanas (FMC), foi implementado um programa de graduação para outorgar o título em Sociologia com concentração em Serviço Social na Universidade de Havana, prevendo uma formação com duração de seis anos. Dois anos depois a Universidade em Santiago de Cuba implantou um programa similar.

A partir da experiência profissional dos trabalhadores sociais e da observação dos programas de universidades latino-americanas e europeias, foi possível elaborar um plano de estudo que desse conta das limitações apresentadas nos programas dos cursos técnicos em trabajo social. Dessa forma, elaborou-se um conjunto de matérias que tivessem uma sólida base de teoria sociológica, preparação metodológica e atividades de pesquisa, com vistas a se apopriar de ferramentas sociológicas que ampliassem a atuação profissional e a leitura da realidade cubana. $\mathrm{O}$ curso de Sociologia contava com 44 disciplinas, sendo dezesseis específicas de Serviço

17. Informação verbal, cf. nota 3 . 
Social (Gutierrez e Barroso, 2005). As disciplinas específicas em Serviço Social estavam estruturadas da seguinte forma:

Figura 1

\begin{tabular}{|c|c|c|c|c|}
\hline $1^{\circ}$ ANO & $2^{\circ}$ ANO & $3^{\circ}$ e $4^{\circ}$ ANO & $5^{\circ}$ ANO & $6^{\circ}$ ANO \\
\hline Filosofia & Demografía & $\begin{array}{l}\text { Serviço Social I } \\
\text { (intervenção na } \\
\text { comunidade) }\end{array}$ & $\begin{array}{l}\text { Sociologia e a } \\
\text { Família }\end{array}$ & $\begin{array}{l}\text { Trabalho de } \\
\text { Conclusão de } \\
\text { Curso }\end{array}$ \\
\hline Economia Política & $\begin{array}{l}\text { Métodos } \\
\text { sociológicos }\end{array}$ & $\begin{array}{l}\text { Serviço Social II } \\
\text { (intervenção com } \\
\text { grupos, organizações } \\
\text { e instituições) }\end{array}$ & Sociologia Política & \\
\hline \multirow[t]{2}{*}{$\begin{array}{l}\text { História das } \\
\text { Américas }\end{array}$} & Estatística & $\begin{array}{l}\text { Serviço Social III } \\
\text { (intervenção com } \\
\text { indivíduos e famílias) }\end{array}$ & Antropologia & \\
\hline & & $\begin{array}{l}\text { História do Serviço } \\
\text { Social }\end{array}$ & Sociologia e Saúde & \\
\hline
\end{tabular}

Fonte: Strug e Teague (2002) (elaboração própria).

Além do curso de Sociologia, o curso de Reabilitação Social e Terapia Ocupacional também abriu saídas para a formação em Trabajo Social, o curso cuja duração de cinco anos contempla um plano de estudos com 49 matérias. As matérias abarcam desde os princípios e conceitos básicos de Serviço Social e Terapia Ocupacional até as formas de interpretação dos problemas sociais, das inaptidões dos sujeitos, das frustrações daqueles que sofrem de transtornos psiquiátricos, deficiências sensoriais e dos pacientes geriátricos que requerem um processo de reabilitação psicossocial e integração à comunidade (Strug e Teague, 2002).

A partir de 2000 iniciou-se em Cuba um processo conhecido como "Batalha das Ideias", concebido como um sistema de diversos programas dirigidos a fortalecer e enriquecer a consciência política do povo cubano. Com esse intuito, Fidel Castro convoca a União de Jovens Comunistas (UJC) para promover programas revolucionários. Para tanto, foram criadas as "Brigadas Universitárias de Trabajo Social", ou seja, trata-se das Escolas de Formação em Trabajo Social (EFTS), ini- 
cialmente criadas na cidade de Cojimar. Posteriormente as EFTS seriam abertas em Villa Clara, Holguín e Santiago de Cuba. ${ }^{18}$

A duração do curso é de um ano. As disciplinas que compõem o plano de estudos das escolas são: Introdução à Psicologia, Sociologia Urbana e Prevenção Social, Serviço Social Comunitário, Psicologia Social e Comunitária, Introdução ao Direito e Comunicação Social, entre outros seminários e oficinas realizados para melhorar as técnicas de intervenção. Os estudantes das EFTS ficaram conhecidos como "emergentes", visto que o objetivo das escolas era dar resposta aos problemas emergentes mais sérios (Jubán et al., 2009).

Gutierrez e Barroso (2005, p. 12) apresentam os principais objetivos das EFTS a partir de quatro grupos:

1. Contribuir a la formación de jóvenes a través del conocimiento y habilidades específicas; dotándolos de una preparación metodológica y técnica que los capacitara para el ejercicio de actividades propias del trabajo social. 2. Posibilitar la continuación de estudios y formación de los jóvenes egresados de estas escuelas. 3. Responder a la acumulada demanda de empleo por parte de este sector poblacional. 4. Utilizar esta nueva fuerza laboral para vincularla a proyectos de transformación en las distintas esferas de la vida social y para brindar una atención directa a personas, familias y colectivos con necesidades sociales asociadas a las distintas situaciones de desventaja social.

Durante os trabalhos de campo orientados por docentes, os alunos realizam "ações preventivas" e "proativas", ou seja, fazem visitas domiciliares e entrevistas com jovens e famílias de bairros carentes para determinar a prevalência de problemas e avaliar o nível de necessidade dos serviços sociais. Além dessas atividades, os alunos participam de projetos sociais e campanhas de saúde pública do governo. Exemplos disso são as campanhas de vacinação e erradicação do mosquito da dengue. Depois de formados, os jovens ganham uma oportunidade de trabalho, comprometendo-se a atuar na comunidade de origem com crianças e adolescentes, entre outros grupos que passam por algum tipo de risco social. Na sua grande maioria, os jovens que fazem a EFTS decidem fazer a graduação em Sociologia para adquirir o grau de licenciado. ${ }^{19}$

Gutierrez e Barroso (2005, p. 13) elucidam o quão importante foi a formação desses jovens nas Escolas de Formação de Trabalhadores Sociais:

18. Informação verbal, cf. nota 3 .

19. Idem. 
Sin lugar a dudas que la inauguración de estas escuelas há posibilitado reinsertar a más de 6000 jóvenes nuevamente en la sociedad, brindándoles una profesión, empleo con un salario decoroso, la posibilidad de continuar estudios universitarios. Al mismo tiempo, ellos han realizado tareas de gran importancia para el país, en particular las referidas al trabajo con jóvenes, niños y ancianos. Pero estos resultados positivos no significan que lo alcanzado no esté exento de aspectos que pueden ser susceptibles de cambio. por ejemplo: puede crearse la falsa imagen de que los graduados de estas escuelas son trabajadores sociales aptos para trabajar en todas las dimensiones de la profesión, en estas escuelas solo se crean un conjunto de habilidades para realizar diagnósticos a un nivel elemental. (grifos meus)

Segundo Jubán et al. (2009), em 2004 o Centro de Estudos para o Trabalho Comunitário da Universidade de Camaguey apresentou uma revisão do programa de mestrado com o intuito de formar mestres capazes de transformar os contextos onde atuam por meio de serviços sociais que contribuam para melhorar a qualidade de vida da população, bem como, permitia a preparação e a formação dos profissionais de várias áreas das ciências sociais e humanas no exercício do Serviço Social, haja vista a pouca procura dos técnicos em Serviço Social causada pela inexistência do curso em nível de graduação.

Portanto, foi a partir do final da década de 1990 que o processo de institucionalização da profissão de "Trabajo Social" em Cuba ganhou ênfase: "El objectivo principal es pasar de bienestar para la transformación social, convirtiendo cada uno en la propia transformación de la materia, esta es la filosofía de la práctica de los Trabajadores Sociales".

Segundo entrevista realizada em $2007^{20}$ com Mabel Díaz Vásquez e Ismael de La Cruz Ávila, responsáveis pelo Programa de Trabajadores Sociales de Havana e Guantánamo, o objetivo é promover a ação social conscientizadora centrada nas necessidades das pessoas e na transformação das causas dos problemas sociais em cada contexto. Em vez de o sujeito procurar os serviços do assistente social, será o profissional que atuará em cada bairro, buscando identificar e intervir nos problemas sociais, a fim de realizar trabalhos de grupo com os indivíduos com o intuito de responsabilizá-los pela própria transformação. Nesse sentido, o assistente social implementará políticas e serviços sociais na comunidade sempre comprometido com a emancipação do projeto revolucionário. Segundo a palestra El Trabajo Social em Cuba, realizada em maio de 2011, em Havana, foram apontados os preceitos éticos dos trabalhadores sociais, quais sejam:

20. Disponível em: $<$ http://www.cubainformacion.tv/index.php?Itemid=86\&id=4406\&option=com content\&task=view $>$. Acesso em: 30 jun. 2011. 
1. Actuar con fidelidad a la Patria. Contribuir conscientemente a defender la obra de la Revolución y el socialismo, ser fieles a sus principios y valores, defenderlos al precio de cualquier sacrificio. 2. Cultivar la honradez, el honor y la dignidad. Rechazar enérgicamente prebendas u ofertas que atenten contra ello. Abstenerse de utilizar su cargo para obtener ventajas y privilegios ilegítimos. 3. Cumplir como cuestión de honor, los compromisos contraídos como miembros del Programa de Trabajadores Sociales. 4. Cumplir y fomentar la disciplina y el respeto consciente de las normas éticas y legales de nuestra sociedad, y las que se establezcan en el Programa en correspondencia con las responsabilidades de los trabajadores sociales. 5. Por la sencillez y la ausencia de todo rasgo de ostentación y de hábitos Caracterizarse consumistas, ajenos a los ideales de justicia social por los que deben luchar los trabajadores sociales. 6. Practicar el respeto a la dignidad de las personas, sobre la base del valor intrínseco del ser humano, con independencia de su condición económica, cultural, educacional, de salud, sexo, creencia religiosa, edad, ideología, situación jurídica, color de la piel, o de cualquier otra índole. 7. Ser veraces en los informes que se rinden sobre el trabajo y con la información dada a la población en cumplimiento de su desempeño como trabajador social. 8. No realizar promesas infundadas. Analizar las posibilidades de solución de los problemas, sobre bases objetivas y cuidar de no crear falsas expectativas en las personas. 9. Respetar y cuidar la privacidad de las informaciones de las personas, obtenidas en razón del desempeño del trabajo social, y al propio tiempo, proteger y viabilizar la información que se requiera en interés de la atención a los problemas sociales. 10. Defender los principios de justicia social. Trabajar con responsabilidad y creatividad revolucionaria en función de las transformaciones sociales que se correspondan con los fines de justicia social y en el empeño de que no quede un solo ciudadano abandonado a su suerte en la sociedad. ${ }^{21}$

Atualmente existem em Cuba em média de 42 mil trabajadores sociales, dos quais $70 \%$ são mulheres. Os espaços de atuação profissional são: nas comunidades, por meio dos conselhos populares existentes em cada bairro, nas instituições educacionais, na habitação, na saúde e nas instituições penitenciárias. Desde 1995 circula a revista Temas: Cultura, Ideología, Sociedad, ${ }^{22}$ um importante espaço para refletir e publicar os ideais do Serviço Social cubano (Vázquez e Ávila, 2007). ${ }^{23}$

21. Informação verbal, cf. nota 3; grifos meus.

22. "Temas se publica, desde enero de 1995, con el propósito de constituir un espacio para la reflexión crítica y el debate de ideas, en torno a los problemas de la cultura y el pensamiento social contemporáneos en Cuba y en el mundo. Su perfil abarca las artes y las letras, los problemas de las ciencias sociales y humanísticas, la teoría política y la ideología.” Disponível em: $<$ http://www.temas.cult.cu/temas.php $>$. Acesso em: 30 jun. 2011.

23. Através do meio de comunicação: "Cubainformación” (projeto de informação alternativa sobre Cuba baseado em quatro mídias: televisão, Internet, rádio, jornal, revistas e notícias na web. Utilizado como 


\section{Algumas considerações}

Em Cuba, a profissão de assistente social está em processo de construção. Historicamente, observou-se que tem existido uma ruptura entre a teoria e a prática no Serviço Social cubano, prejudicando-o em sua intervenção profissional. Afinal, conforme abordado no decorrer deste artigo, os profissionais graduados nas Escolas de Trabalhadores Sociais (EFTS) estão habilitados apenas para a prestação de apoio social, ou seja, nas práticas de bem-estar à comunidade e para identificar os problemas sociais existentes nos bairro. Ainda que se tenham as formações em Sociologia e Reabilitação Social e Terapia Ocupacional com especialização em Serviço Social, os debates da categoria profissional têm insistido na importância de ter uma formação universitária específica em Serviço Social, que permita ao profissional compreender que toda prática deve ser referenciada em uma teoria, que deve orientar e iluminar tal prática.

Gutierrez e Barroso (2005, p. 3) apresentam, em relação ao Serviço Social, algumas dificuldades epistemológicas que devem ser pesquisadas pelos estudiosos da área, tais como:

1. La promiscuidad de su objeto, lo comparte con otras ciencias. 2. La indefinición de su orientación, predomina una óptica pragmática o por el contrario una ideologizante. 3. El objeto de intervención se designa a través de la evidencia empírica, tomada directamente de la realidad, sin que medie ningún proceso de teorización. 4. La conceptualización que se realiza se fundamenta en conceptos tomados de otras ciencias afines, no hay un interés por producir una sistematización que trascienda la experiencia práctica. 5. El objeto de intervención se identifica totalmente con el sujeto portador del problema, y en ocasiones se pierden de vista marcos sociales más amplios. 6. La existencia de préstamos disciplinares tanto en el orden de la teoría, como del método. 7. Es una actividad socialmente construida, de ahí la centralidad de la categoría de acción social. 8. Se desarrolla en contextos históricos diferentes, por lo que constantemente hay que validar lo universal, con lo particular principales momentos en la profesionalización.

A partir do projeto social revolucionário orientado pelo comandante-chefe — Fidel Castro - a avaliação que se tem feito em torno da prática dos assistentes

\footnotetext{
ferramenta do Movimento de Solidariedade com Cuba para informar a realidade do país) foi realizado uma entrevista com Mabel Díaz Vásquez e Ismael de La Cruz, ambos são presidentes do Programa de Trabajadores Sociales de Havana e Guantánamo. A entrevista, com duração de cinquenta minutos, abordou a profissão Trabajo Social em Cuba. Disponível em: <http://www.cubainformacion.tv/index.php?Itemid= 86\&id=4406\&option=com_content\&task=view $>$ (parte 1) e $<$ http://www.mefeedia.com/watch/29190396 $>$ (parte 2). Acesso em: 30 jun. 2011.
} 
sociais se firma nos princípios da Revolução, de justiça e da equidade social. Para alcançá-los, faz-se necessário que o assistente social se alie à sociedade e utilize como principais armas as próprias potencialidades das pessoas e o seu caráter emancipador.

Ao final da mesa-redonda realizada no Congreso Internacional de Trabajo Social (maio de 2011, Havana), foram destacadas algumas projeções que definem o caminho a ser seguido pelos profissionais, como serão detalhadas a seguir.

A primeira projeção de trabalho diz respeito à construção do projeto ético-político da profissão, ${ }^{24}$ cuja prática deve ser comprometidoa com a ideología emancipadora da Revolução Cubana. Para tanto, foram problematizados dois enfoques para a prática profissional: caminhar para um enfoque opressor ou emancipador. Define-se como enfoque opressor qualquer ação profissional que manipule as pessoas, que não explore as potencialidades dos indivíduos, que os trate como objetos, e não como sujeitos de sua transformação. O enfoque emancipador diz respeito à prática profissional comprometida com o projeto ético-político de crescimento e desenvolvimento humano.

A segunda projeção é ter uma ação conscientizadora/transformadora, ou seja, qualquer prática assistencialista ou paternalista é uma prática nociva, que invalida e trata as pessoas como objeto, sem resolver em definitivo as causas reais dos problemas. Portanto, é necessária uma posição em que as próprias pessoas se conscientizem e identifiquem as reais causas do mal-estar que aparece na vida cotidiana. Somente a partir de um processo de conscientização é que as pessoas alcançarão elas próprias um processo reflexivo da vida cotidiana identificando as verdadeiras causas dos seus problemas e das contradições existentes na vida diária, adquirindo uma atitude consciente com relação às mudanças. Nesse sentido, os trabalhadores sociais não serão os únicos responsáveis pela resolução de todos os problemas e pela transformação social.

A terceira projeção é a necessidade de o assistente social ser de caráter preventivo e proativo. O profissional não pode reacionar, mas realizar um processo ativo, buscando identificar as causas que se traduzem em problemáticas.

A quarta projeção é a necessidade de legitimar o papel do "trabajador social" como dinamizador das políticas sociais. O conceito de trabajo social que vem sendo defendido é o de uma disciplina científica em formação, uma profissão que se responsabiliza por prevenir e transformar problemáticas sociais que aparecem

24. Salienta-se que a prática do Serviço Social em Cuba está amparada por leis de diferentes organismos existentes no país. Somente em 2008 o Programa de Assistentes Sociais aprovou o Código de Ética para a prática dos chamados qualificados assistentes sociais (Jubán, 2009). 
nos indivíduos, grupos e comunidades. Contudo, a ação transformadora deve ser a partir da participação, da implementação das políticas sociais, da conscientização e educação social.

Estas políticas y los servicios sociales tinen la suerte de estar en un país que está comprometido con las políticas sociales y las sanciones por no solamente asistir a una minoría social. Cuba tiene un Estado con políticas que tienen un carácter popular, pero está claro que esta compleja relación de los servicios sociales, políticos y sociales también hay contradicción, es decir, que la realidad social que se presenta es problemático, es dinámico, es heterogéneos, sin embargo, las políticas no son homogéneos, estáticas en el tiempo y por lo tanto produce una contradicción, porque hay un conjunto de necesidades, en el que las políticas del país no ofrecen respuestas. ${ }^{25}$

Nesse sentido, o espaço de atuação do assistente social é, precisamente, na mediação entre as necessidades da população e as políticas sociais, a fim de apontar alternativas e respostas a tais necessidades, as quais são sempre dinâmicas e crescentes.

A quinta projeção aponta e valoriza o Serviço Social no âmbito comunitário, no sentido de desenvolver um projeto coletivo, fomentando a consciência crítica dos indivíduos, grupos e comunidade.

Por último, a sexta projeção diz respeito à formação dos assistentes sociais cubanos, pois não há carreira de Serviço Social em Cuba. A priori, é urgente e imprescíndivel a formação universitária para essa carreira.

Diante dessas projeções e do recorrido histórico realizado neste artigo, ficou visível que a profissão em Cuba é projetada a partir do trabalho com casos de indivíduo, de grupo e de comunidade. O método de intervenção social está relacionado com a prática profissional, entendida como formas de ação que têm como finalidade a obtenção de determinadas práticas, a modificação de coisas ou situações reais (Ander-Egg, 2010). Haja vista que a profissão possui forte vínculo com a área médica, percebe-se que o método de ação tem por base o modelo clínico terapêutico da medicina, que influencia decisivamente na configuração e no desenvolvimento da metodologia de intervenção social: estudo, diagnóstico e tratamento (Ander-Egg, 1995).

A prática profissional está mais voltada para as bases doutrinárias do que científicas, utilizando o desenvolvimento de caso, grupo e comunidade e conduzindo à melhoria das condições imediatas do meio, contando com a participação dos

25. Informação verbal, cf. nota 3. 
indivíduos e grupos como coparticipantes na execução dos projetos e das atividades, unidos pelo bem comum. Tais atividades buscam um padrão ético-moralizador do indivíduo e de sua família, ajustando-os aos preceitos revolucionários do comandante-chefe Fidel Castro.

Por outro lado, alguns intelectuais propõem o estudo e a necessidade de mudar a prática profissional, de forma a superar as ações fragmentadas e criar mecanismos de participação da população para o controle dos serviços sociais e para exigir direitos sociais. Além disso, é apresentada a necessidade de realizar uma leitura mais crítica da realidade com base nas teorias sociológicas e de acordo com o contexto sócio-histórico em que estão inseridos. Entretanto, faz-se necessário que o profissional esteja qualificado tecnicamente, com propriedade teórica para embasar a leitura de realidade, bem como com um projeto-ético-político estabelecido. Nesse sentido, pode-se intuir que há uma tentativa, por parte de alguns intelectuais da área, de reconceituação do trabajo social cubano, com base nas experiências de outros países latino-americanos.

Recebido em 5/9/2011 - Aprovado em 13/9/2011

\section{Referências bibliográficas}

ANDER-EGG, Ezequiel. Humanismo y trabajo social. México: Universidad Autónoma de Sinaloa, 2010. 87 p.

. Introdução ao trabalho social. Brasil: Petropólis, 1995.

CAMPAGNUCIO, Hélio. Precisamos olhar para Cuba sem preconceitos. Artigos organizados em 2004 (Brasília) pelo Núcleo de Estudos sobre Cuba - Nescuba. Disponível em: $<$ http://e-groups.unb.br/ceam/nescuba/artigos/pano307.htm>. Acesso em: 24 jun. 2011.

ESPINOSA, Eugênio. Cuba: una alternativa al neoliberalismo. Artigos organizados em 2004 (Brasília) pelo Núcleo de Estudos sobre Cuba - Nescuba. Disponível em: <http://vsites. unb.br/ceam/nescuba/artigos/pano206.htm>. Acesso em: 23 jun. 2011.

GALLARDO, V. A. M.; VILABOY, S. G.; ARANA, R. G. Revoluciones latinoamericanas del siglo $X X$ : síntesis histórica y análisis historiográfico. México: Universidad Michoacana de San Nicolás de Hidalgo, 2006. 471 p.

GUTIERREZ, Teresa Muñoz; BARROSO, Lourdes de Urrutia. El desarrollo del trabajo social en Cuba. Artigos organizados em 2005 (Brasília) pelo Núcleo de Estudos sobre Cuba 
— Nescuba. Disponível em: <http://e-groups.unb.br/ceam/nescuba/artigos/pano307.htm>. Acesso em: 24 jun. 2011.

HERNÁNDEZ, Rosa M. V. La familia como clave comprensiva de los procesos de (re) producción de la pobreza: las políticas sociales como mediadoras en el contexto cubano. Serviço Social \& Realidade, Franca, v. 18, n. 2, p. 11-30, 2009. Disponível em: <http://www. franca.unesp.br/ssrealidade/SSR_18N2.pdf>. Acesso em: 27 jun. 2011.

JUBÁN, Odalys de La Luz González et al. Formación y práctica profesional del trabajo social en Cuba. Boletín Electrónico. Escuela de trabajo social - Universidad de Costa Rica. Disponível em: <www.ts.ucr.ac.cr>. Acesso em: $1^{\circ}$ mar. 2009.

LIMA, Leila. Centro Latinoamericano de Trabajo Social y de la Asociación Latinoamericana de Trabajo Social. Cuba y el trabajo social. Acción Crítica, Lima, n. 13, p. 1-5, 13 jul. 1983. Disponível em: <http://www.ts.ucr.ac.cr/binarios/accioncritica/ac-cr-013-10.pdf>. Acesso em: 26 jun. 2011.

MORAIS, Fernando. A ilha. São Paulo: Alfa-Omega, 1976. v. 3.73 p.

STRUG, David; TEAGUE, Walter. Nuevas orientaciones en la educación de trabajo social en Cuba: ¿Qué puede aprender la comunidad internacional de trabajo social? Social Work Today, Nova York, n. 4, p. 1-9, 2 set. 2002. Disponível em: <http://www.socialworktoday. com>. Acesso em: 25 jun. 2011.

SÁNCHEZ, Yoani. De Cuba, com carinho. São Paulo: Contexto, 2009.

VÁSQUEZ, Mabel D.; ÁVILA, Ismael de la Cruz. El Programa de Trabajadores Sociales de Cuba. In: Mídia alternativa. Disponível em: < http://www.cubainformacion.tv/index.ph p?Itemid=86\&id=4406\&option=com_content\&task=view $>$. Acesso em: 30 jun. 2011.

VICONGRESO INTERNACIONAL DE TRABAJO SOCIAL. In: CONGRESO NACIONAL DE TRABAJADORES SOCIALES DE LA SALUD, 7., CONGRESO NACIONAL, 2. INTERNACIONAL DE REAHABILITACIÓN SOCIAL Y OCUPACIONAL, 6., 2011, Havana, Cuba.

XIX CONVENÇÃO NACIONAL DE SOLIDARIEDADE A CUBA, 2011, São Paulo, Brasil. Vitória de Cuba em Playa Girón: 50 anos. Nos dias 23 a 26 de junho de 2011 na cidade de São Paulo, Brasil.

YAZBEK, Maria Carmelita. Fundamentos históricos e teórico-metodológico do Serviço Social. In: Serviço Social: direitos sociais e competências profissionais. Brasília: Cefess/ ABEPSS, 2009. p. 144-163. 